\title{
A Macrocyclic 2,19-Dioxo[3.3](3,3')azobenzolophane by Transition-Metal Carbonyl Complex-Mediated CO Insertion and Cyclization
}

\author{
Jürgen Schmiegel and Hans-Friedrich Grützmacher* \\ Fakultät Chemie der Universität Bielefeld, \\ Postfach 8640, Universitätsstraße, D-4800 Bielefeld 1 \\ Received February 9, 1990
}

Key Words: Tetraaza[3.2.3.2]metacyclophane / Transition-metal carbonyl complexes / Photoisomerism

2,19-Dioxo[3.3](3,3')azobenzolophane (5) has been obtained in a total yield of $18 \%$ by way of $\mathrm{CO}$ insertion and cyclization of 1,2-bis[3-(bromomethyl)phenyl]-4,4-dimethyl-3,5-pyrazolidinedione (1) using $\mathrm{Co}_{2}(\mathrm{CO})_{8}$ in acetonitrile followed by the removal of the $N$-protecting 4,4-dimethylmalonyl groups. 5 is obtained predominantly as the trans/trans isomer $\mathbf{5 a}$ and can be isomerized by irradiation with $\lambda=369 \mathrm{~nm}$ to a mixture of nearly equal amounts of the trans/trans, cis/trans, and cis/cis isomers $5 \mathrm{a}, 5 \mathrm{~b}$, and $5 \mathrm{c}$. The thermal isomerization back to $5 \mathrm{a}$ is slow but fast upon irradiation with $\lambda=443 \mathrm{~nm}$.
Medium and macrocyclic cyclophanes are routinely prepared from open-chain precursors by cyclization involving nucleophilic substitution ${ }^{1}$. In particular the reaction between sulfides and benzyl halides can be used for an efficient cyclophane synthesis. We have used this method in combination with the rigid-group principle ${ }^{2)}$ and with high dilution techniques ${ }^{3)}$ for the synthesis of a series of diazacyclophanes ${ }^{4)}$ containing an azobenzene moiety, but up to now all attempts to effect a sulfur extrusion from these thia- and dithiadiazacyclophanes failed ${ }^{\text {s) }}$. The macrocyclic azobenzolophanes undergo an interesting cis/trans photoisomerism which affects the shape of the molecular cavity, and the synthesis of azobenzolophanes lacking the weak benzylic $\mathrm{C}-\mathrm{S}$ bond would be of some advantage for photochemical experiments. However, the synthesis of sulfur-free diazacyclophanes by a cyclization and a $\mathrm{C}-\mathrm{C}$ bond formation by nucleophilic substitution ${ }^{1)}$ has not been successful ${ }^{\text {s) }}$. The reductive coupling of benzyl halides using various low-valent metals represents an elegant method of a $\mathrm{C}-\mathrm{C}$ bond formation ${ }^{6}$. However, attempts to use these methods for the preparation of cyclophanes from 1,3-bis[4-(brommethyl)phenyl]propane used as a model compound have failed although good yields have been obtained for the coupling of benzyl bromide under the same reaction conditions? ${ }^{7}$. This agrees with the results recently published by Wey and Butenschön ${ }^{8)}$.

Transition-metal carbonyl complexes are known to catalyze the intermolecular formation of carbon-carbon bonds by $\mathrm{CO}$ insertion into carbon-halogen bonds ${ }^{9}$. By treatment of dihalides with these reagents an insertion of $\mathrm{CO}$ and the intramolecular formation of small cyclic ketones $(n=5-7)$ occur ${ }^{10}$. However, again no cyclic products are obtained in a reaction of 1,3-bis[4-(brommethyl)phenyl]propane with $\mathrm{Ni}(\mathrm{CO})_{4}$ or $\mathrm{Co}_{2}(\mathrm{CO})_{8}$ under various reaction conditions ${ }^{7}$. Instead, the corresponding carboxylic acids are formed by the known sequence of $\mathrm{CO}$ insertion and hydrolytic cleavage of the metal-carbon bonds ${ }^{6}$. Apparently, $\mathrm{CO}$ insertion and cyclization require a rather special stereochemistry of the organic dihalide. Therefore, we have tried a combination of the rigid-group principle and the $\mathrm{CO}$ insertion method to prepare sulfur-free diazacyclophanes by using 1,2-bis[4(brommethyl)phenyl]-4,4-dimethyl-3,5-pyrazolidinedione and 1,2-bis[3-(brommethyl)phenyl]-4,4-dimethyl-3,5-pyrazolidinedione (1), respectively, which have been used before as precursors for the synthesis of diazameta- and -paracyclophanes ${ }^{4 a, b)}$. While the para-substituted derivative does not react at all with $\mathrm{Ni}(\mathrm{CO})_{4}$ or $\mathrm{CO}_{2}(\mathrm{CO})_{8}$ in dry acetonitrile ${ }^{11)}$ the reaction of 1 with these metal carbonyls under the same conditions affords small amounts of a dimer of 1 and a twofold $\mathrm{CO}$ insertion. No traces of a monomeric cyclization product have been detected even by a mass spectrometric analysis using a fractional evaporation of the reaction mixture. Higher yields are obtained with $\mathrm{Co}_{2}(\mathrm{CO})_{8}$, and by use of two equivalents of this reagent and $\mathrm{LiBr}$, causing a disproportion into the reactive species $\mathrm{Co}(\mathrm{CO})_{4}^{-}$and $\mathrm{CoBr}_{2}$,

Scheme 1
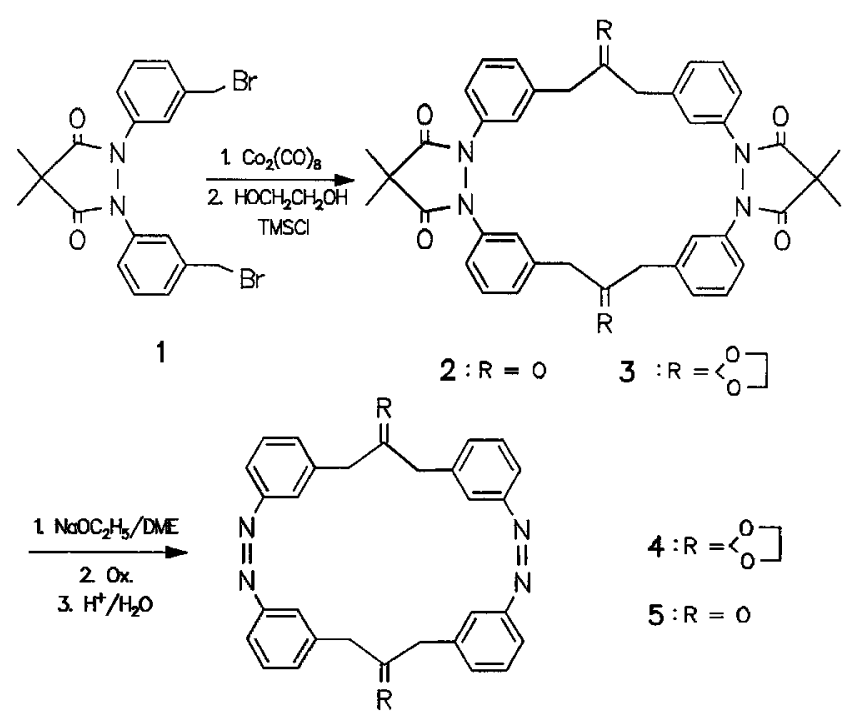
10,11:27,28-bis(dimethylmalonyl)-2,19-dioxo-10,11,27,28tetraaza[3.2.3.2](1,3)(1,3)(1,3)(1,3)cyclophane (2) is obtained in $35 \%$ yield. To our knowledge this is the first preparation of a cyclophane by cyclization and insertion of $\mathrm{CO}$ generated from a transition-metal carbonyl into a benzyl dihalide. The use of high-dilution techniques neither improves the yield nor produces any monomeric product.

Usually, the removal of the $N$-protecting dimethylmalonyl group of the hyrdrazobenzolophanes can be achieved by treatment with $\mathrm{C}_{2} \mathrm{H}_{5} \mathrm{ONa} / \mathrm{DME}^{4 b}$, but in the case of 2 deprotonation and subsequent polymerisation may easily occur at the benzylic methylene groups adjacent to the carbonyl groups under the strongly alkaline conditions. Hence, the carbonyl groups of 2 have been protected by nearly quantitative conversion into the bis-dioxolane 3 by treatment with ethylene glycol/chlorotrimethylsilane ${ }^{12)}$. The tetraaza[3.2.3.2]cyclophane 4 is obtained in satisfactory yields by ethanolysis and air oxidation of $\mathbf{3}$ under the usual conditions $^{4 b}$. The acetal moieties of $\mathbf{4}$ have proved to be unusually stable, and the cleavage of the carbonyl protecting groups requires treatment with acidified silica gel ${ }^{13)}$ for several days. Eventually, 2,19-dioxo-10,11,27,28-tetraaza[3.2.3.2](1,3)(1,3)(1,3)(1,3)cyclopha-10,27-diene (2,19-dioxo[3.3] $\left(3,3^{\prime}\right)$ azobenzolophane, 5 ), is obtained in a total yield of $18 \%$ starting from 1 .

The macrocyclic azobenzolophane 5 exhibits an interesting stereochemistry. Besides a cis/trans isomerism at the azo groups several conformers with a syn and anti orientation of opposite pairs of the benzene rings appear feasible. Rau et al. ${ }^{14)}$ have studied the stereochemistry and the photoisomerization of the related paracyclophane 2,19-dithia[3.3] $\left(4,4^{\prime}\right)$ azobenzolophane, which prefers a bis-trans-azo configuration with sligthly tilted benzene rings. A similar configuration has been reported for [2.2] $\left(4,4^{\prime}\right)$ azobenzolophane ${ }^{15)}$. Both para-azabenzolophanes are mainly photoisomerized the cis/cis-azo isomer while the cis/trans isomer is only a transient species which is quickly converted into the trans/trans isomer ${ }^{14,15)}$. The configurations at the azo groups and the conformations of meta-azobenzolophane 5 before and after a photoisomerization can be readily studied by ${ }^{1} \mathrm{H}-\mathrm{NMR}$ spectroscopy.

In view of the many possible conformations of the macrocyclic compound 5 its $300-\mathrm{MHz}{ }^{1} \mathrm{H}-\mathrm{NMR}$ spectrum is remarkably simple and manifests a symmetric ground state conformation of 5 . The singlet of the benzylic protons at $\delta=3.77$ shows clearly that only one isomer of 5 is predominantly obtained by the synthesis. The region of the aromatic protons exhibits the typical signal pattern of a meta-substituted benzene ring with only one doublet of the protons adjacent to the azo group appearing at $\delta=7.82$. This is typical of a trans-meta-azotoluene while the same protons of the cis isomer give rise to a doublet at $\delta=6.52^{4 b)}$. Furthermore, each of the other protons at the aromatic rings also exhibits only one signal (Table 1). Clearly, the steric situation is identical for all four aromatic rings which requires a trans-trans configuration at both azo groups (Scheme 2). In addition, the phenyl groups either rotate unconstrainedly through the macrocyclic ring to account for the identical resonance lines of the corresponding protons at the four rings or, more likely, the phenyl groups are fixed in a symmetric conformation. In the latter case the low-field position of the singlet at $\delta=7.59$ due to the isolated protons $\mathrm{H}_{i}$ between the bridges indicates a syn conformation for both pairs of benzene rings as in $\mathbf{5 a}$ and excludes the anti/anti conformation $5 \mathbf{a}^{*}$. However, in any case the singlet of the benzylic protons of $\mathbf{5 a}$ indicates some conformational mobility, probably a wobbling motion of the $\mathrm{CH}_{2}-\mathrm{CO}-$ $\mathrm{CH}_{2}$ bridges.

Scheme 2
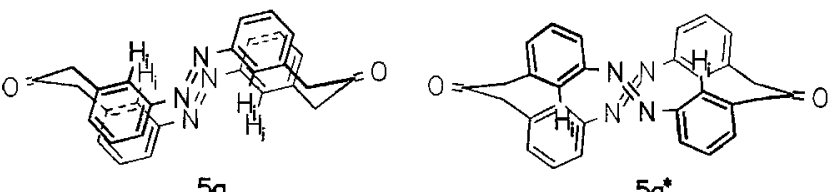

50

$50^{*}$

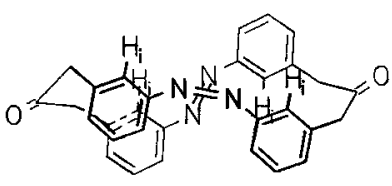

$5 b$

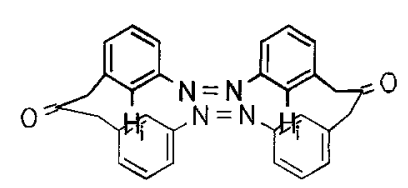

$5 c$
Table 1. 'H-NMR data ( $\delta$ values) of isomeric 2,19-dioxo[3.3]$\left(3,3^{\prime}\right)$ azobenzolophanes 5

\begin{tabular}{|c|c|c|c|c|c|c|}
\hline & Config. & $\mathrm{H}_{\mathrm{bzl}}$ & $\mathrm{H}_{\mathrm{A}}$ & $\mathrm{H}_{\mathrm{B}}$ & $\mathrm{H}_{\mathrm{C}}$ & $\mathrm{H}_{\mathrm{i}}$ \\
\hline $5 \mathbf{a}$ & $\operatorname{trans} / \operatorname{trans}$ & 3.77 & 7.82 & 7.48 & 7.34 & 7.59 \\
\hline $5 \mathbf{b}$ & cis/trans & 3.78 & $6.28 / 7.74$ & $6.92 / 7.48$ & $6.62 / 7.41$ & $6.71 / 7.48$ \\
\hline $5 c$ & ignment 0 & 3.80 & 6.77 & $\begin{array}{r}7.29 \\
\end{array}$ & 7.00 & 6.36 \\
\hline
\end{tabular}

Irradiation of a solution of 5 in $\mathrm{CDCl}_{3}$ with $\lambda=369 \mathrm{~nm}$ gives rise to a cis/trans isomerisation which has been examined by ${ }^{1} \mathrm{H}$ NMR. A mixture of three isomers in the photostationary state has been detected in the $300-\mathrm{MHz}^{1} \mathrm{H}-$ NMR spectrum (Table 1). This is most clearly seen from the splitting of the signals of the benzylic protons into three closely spaced singlets, and from the integrals of these signals at $\delta=3.77,3.78$, and 3.80 a composition of 30,30 , and $40 \%$ of the three isomers is deduced. The isomer exhibiting the benzylic proton signal at $\delta=3.78$ belongs to the trans/ trans isomer 5a whose other signals are easily identified in the spectrum. The photochemically induced trans/cis isomerization at the two azo groups of 5 a should produce a cis/trans and a cis/cis isomer $\mathbf{5 b}$ and $\mathbf{5 c}$, respectively. In fact, the $300-\mathrm{MHz}{ }^{1} \mathrm{H}-\mathrm{NMR}$ spectrum (Table 1) of the mixture shows a series of signals between $\delta=6$ and 7 which can be attributed to a cis-meta-azotoluene moiety. A careful evaluation of the spectrum taking also into account the different concentrations of the isomers reveals that the cis/cis 
isomer 5c predominates with about $40 \%$ while the mixed cis/trans isomer $\mathbf{5 b}$ is present to about $30 \%$.

The singlet of the $\mathrm{H}_{\mathrm{i}}$ of the cis/cis isomer 5c appears at $\delta=6.36$, and this high-field shift is characteristic of the anti conformation of metacyclophanes ${ }^{16}$. Since only one signal is observed for $\mathrm{H}_{\mathrm{i}}$ and only one set of signals for the other protons on the aromatic rings both halves of $5 \mathrm{c}$ are in an anti conformation (Scheme 2). In contrast, the cis/trans isomer $\mathbf{5 b}$ exhibits two sets of signals in the ${ }^{1} \mathrm{H}-\mathrm{NMR}$ spectrum and two singlets for the $\mathrm{H}_{\mathrm{i}}$ which appear at $\delta=6.71$ and 7.48 , respectively, the latter one somewhat concealed by a multiplet from other protons. Clearly, the two pairs of opposing benzene rings are in a different steric situation and adopt an anti and a syn conformation, respectively (Scheme 2).

Interestingly, only singlets are observed for the benzylic protons of $\mathbf{5 b}$ and $\mathbf{5} \mathbf{c}$. This may be due to a fast wobbling motion of the bridges or some other fast changing conformation, but no low-temperature NMR studies have been performed to investigate this effect.

The [3.3]metaazobenzolophane $\mathbf{5}$ is as easily isomerized by irradiation with $\lambda=369 \mathrm{~nm}$ as the paraazobenzolophanes ${ }^{14,15)}$. However, and in contrast to the paraazobenzolophanes, the photoisomerization of 5 gives rise to a mixture of all three possible isomers in nearly equal amounts. Furthermore, the thermal isomerization back to $5 \mathbf{a}$ is slow and complete only after several days. At the moment it is not clear whether this diverse behavior of $\mathbf{5}$ is due to the carbonyl groups in the bridges or, more likely, to the rather special conformations of the metaazobenzolophane skeleton. In any case, the isomerization of the isomers in the mixture back to 5a occurs on irradiation of the solution with $\lambda=443 \mathrm{~nm}$.

The present results show that it is possible to prepare conveniently a macrocyclic tetraaza[3.2.3.2] $(1,3)(1,3)(1,3)-$ $(1,3)$ cyclophane by cyclization and insertion of $\mathrm{CO}$, generated from a transition-metal carbonyl complex, into a suitable benzyl dihalide. The $\mathrm{CO}$ insertion gives rise to a carbonyl group in the newly formed bridge which offers further possibilities for a synthetic modification.

The financial support of this work by the Fonds der Chemischen Industrie is gratefully acknowledged.

\section{Experimental}

IR: Perkin Elmer 841. - UV: Beckman Spectralphotometer Modell 25. - MS: Varian MAT $311 \mathrm{~A}$ (high resolution) and $\mathrm{CH}$ 5. ${ }^{1}$ H NMR: Bruker AM 300. - Melting points (uncorrected): Elektrothermal melting point apparatus. - Elemental analyses: Microanalytical Laboratory of the university, Perkin-Elmer 240. - Column chromatography: Silica gel 60, 0.063-0.200 mm (Merck), MPLC: Lobar LiChroprep Si $60(40-63 \mu \mathrm{m}$, Merck). - Thinlayer chromatography: Silica gel 60 on Al plates (Merck, $60 \mathrm{~F}$ 254). - All solvents were distilled prior to use and dried by the usual procedures, if necessary.

10,11:27,28-Bis(dimethylmalonyl)-2,19-dioxo-10,11,27,28-tetraaza[3.2.3.2] (1,3) (1,3)(1,3) (1,3)cyclophane (2): $1.42 \mathrm{~g}(4.30 \mathrm{mmol})$ of $\mathrm{Co}_{2}(\mathrm{CO})_{8}$ was dissolved under $\mathrm{N}_{2}$ in $200 \mathrm{ml}$ of dry acetonitrile, then anhydrous $\mathrm{LiBr}$ was added and the mixture warmed to $50^{\circ} \mathrm{C}$ (the color changed from black to blue). $1.0 \mathrm{~g}(2.15 \mathrm{mmol})$ of dibromide 1 in $70 \mathrm{ml}$ of dry acetonitrile was added to the blue solution over a period of $12 \mathrm{~h}$, followed by heating to $80^{\circ} \mathrm{C}$ for $1 \mathrm{~h}$. After filtration the solvent was removed at reduced pressure and the residue hydrolyzed with $200 \mathrm{ml}$ of water and dil. $\mathrm{HCl}$. The aqueous layer was extracted several times with ethyl acetate, the combined extracts were washed with water and dried with $\mathrm{Na}_{2} \mathrm{SO}_{4}$. After evaporation of the organic solvent the chromatography of the residue (petroleum ether/ethyl acetate $1: 1$ ) gave colorless crystals. Yield: $480 \mathrm{mg}(35 \%)$, m.p. $229^{\circ} \mathrm{C}$ (dec., $\mathrm{CH}_{2} \mathrm{Cl}_{2}$ ), $R_{\mathrm{f}} 0.82$ (acetone), 0.18 (petroleum ether/ethyl acetate $1: 1) .-$ IR $(\mathrm{KBr}): \tilde{v}=3428$, $3069,2929,2857,1722,1606,1586,1488,1452,1386,1305,1223$, 1177, 1107, 782, 725, 702, $692 \mathrm{~cm}^{-1}$. - ${ }^{1} \mathrm{H}$ NMR (300 MHz): $\delta=$ 1.52 (s, $\left.12 \mathrm{H}, \mathrm{CH}_{3}\right), 3.41$ (s, $8 \mathrm{H}$, benzyl. $\left.\mathrm{CH}_{2}\right), 6.78(\mathrm{~d}, 4 \mathrm{H}$, aromat. $\mathrm{H}, J=8 \mathrm{~Hz}), 7.04(\mathrm{~s}, 4 \mathrm{H}$, aromat. $\mathrm{H}), 7.25(\mathrm{~m}, 8 \mathrm{H}$, aromat. $\mathrm{H})$. MS: $m / z(\%)=668\left[\mathrm{M}^{+\bullet}\right](100), 669(47), 670(19), 640(8), 362(12)$, 334 (11), 305 (8), 207 (9), 175 (15), 146 (22), 132 (21), 106 (10), 91 (18), $90(11), 89(5), 69(33)$.

\section{$\mathrm{C}_{40} \mathrm{H}_{36} \mathrm{~N}_{4} \mathrm{O}_{6}$ Calcd. 668.26349 Found 668.2633 (MS)}

10,11:27,28-Bis(dimethylmalonyl)-2,19-dioxo-10,11,27,28-tetraaza[3.2.3.2] (1,3)(1,3) (1,3)(1,3)cyclophane 2,2:19,19-Bis(ethylene acetal) (3): $250 \mathrm{mg}(0.37 \mathrm{mmol})$ of 2 was dissolved in a mixture of $20 \mathrm{ml}$ of dry ethanol and $25 \mathrm{ml}$ of freshly distilled ethylene glycol. $1.0 \mathrm{~g}(9.2 \mathrm{mmol})$ of chlorotrimethylsilane was added, and the mixture was stirred under $\mathrm{N}_{2}$ at room temp. for $12 \mathrm{~h}$. After evaporation of the solvents at reduced pressure the residue was hydrolyzcd with $200 \mathrm{ml}$ of water and the aqueous layer extracted several times with ethyl acetate. The combined extracts were washed with watcr and dried with $\mathrm{Na}_{2} \mathrm{SO}_{4}$. After evaporation of the solvent the residuc was used without further purification. Yield: $280 \mathrm{mg}(100 \%)$, m.p. $276^{\circ} \mathrm{C}\left(\mathrm{CH}_{2} \mathrm{Cl}_{2}\right), R_{\mathrm{f}} 0.38$ (petroleum ether/ethyl acetate $1: 1$ ). $-{ }^{1} \mathrm{H}$ NMR (300 MHz): $\delta=1.50\left(\mathrm{~s}, 12 \mathrm{H}, \mathrm{CH}_{3}\right), 3.55\left(\mathrm{~s}, 8 \mathrm{H}\right.$, benzyl. $\mathrm{CH}_{2}$ ), $6.76(\mathrm{~d}, 4 \mathrm{H}$, aromat. $\mathrm{H}, J=8 \mathrm{~Hz}), 7.01(\mathrm{~s}, 4 \mathrm{H}$, aromat. $\mathrm{H}), 7.24(\mathrm{t}$, $4 \mathrm{H}$, aromat. $\mathrm{H}, J=8 \mathrm{~Hz}), 7.33(\mathrm{~d}, 4 \mathrm{H}$, aromat. $\mathrm{H}, J=8 \mathrm{~Hz}$ ). MS: $m / z(\%)=756\left[\mathbf{M}^{+\cdot}\right](20), 712(10), 449(43), 380(24), 379(98)$, $204(16), 146(5), 132(17), 69(21), 44$ (100).

2,19-Dioxo-10,11,27,28-tetraaza[3.2.3.2J(1,3)(1,3)(1,3)(1,3)cyclophane-10,27-diene 2,2:19,19-Bis(ethylene acetal) (4): $100 \mathrm{mg}(0.13$ mmol) of 3 was dissolved in $50 \mathrm{ml}$ of dry 1,2-dimethoxyethane (DME), an excess of $\mathrm{NaOEt}$ was added, and the mixture was stirred at room temp. under $\mathrm{N}_{2}$. The reaction was monitored by TLC and was complete after $12 \mathrm{~h}$. After filtration the solvent was removed at reduced pressure and the residue hydrolyzed with $200 \mathrm{ml}$ of water. The aqueous layer was acidified and extracted several times with ethyl acetate. The combined extracts were washed with water and dried with $\mathrm{Na}_{2} \mathrm{SO}_{4}$. After evaporation at reduced pressure the residue was chromatographed (MPLC, petroleum ether/ethyl acetate 2:1). Yield: $60 \mathrm{mg}(85 \%)$, m. p. $197^{\circ} \mathrm{C}\left(\mathrm{CH}_{2} \mathrm{Cl}_{2}\right), R_{\mathrm{f}} 0.76$ (petroleum ether/ethyl acetate 2:1). $-{ }^{1} \mathrm{H}$ NMR (300 MHz): $\delta=2.96$ (s, $\left.8 \mathrm{H}, \mathrm{OCH}_{2} \mathrm{CH}_{2} \mathrm{O}\right), 4.11\left(\mathrm{~s}, 8 \mathrm{H}\right.$, benzyl. $\left.\mathrm{CH}_{2}\right), 7.46(\mathrm{t}, 4 \mathrm{H}$, aromat. $\mathrm{H}, J=8 \mathrm{~Hz}), 7.56(\mathrm{~d}, 4 \mathrm{H}$, aromat. $\mathrm{H}, J=8 \mathrm{~Hz}), 7.83(\mathrm{~d}, 8 \mathrm{H}$, aromat. $\mathrm{H}, J=8 \mathrm{~Hz}) .-\mathrm{MS}: m / z(\%)=560\left[\mathrm{M}^{+\cdot}\right](9), 488(2)$, 351 (18), 281 (35), 180 (11), 165 (10), 104 (19), 91 (32), 90 (100), 89 (21).

\section{$\mathrm{C}_{34} \mathrm{H}_{32} \mathrm{~N}_{4} \mathrm{O}_{4}$ Calcd. 560.2424 Found 560.2424 (MS)}

2,19-Dioxo-10,11,27,28-tetraaza[3.2.3.2] (1,3) (1,3)(1,3) (1,3) cyclophan-10,27-diene (5): $5.0 \mathrm{~g}$ of silica gel $60(70-230 \mathrm{mesh})$ was deposited in $10 \mathrm{ml}$ of $\mathrm{CH}_{2} \mathrm{Cl}_{2}, 25$ drops of dil. $\mathrm{H}_{2} \mathrm{SO}_{4}$ and 1 drop of conc. $\mathrm{H}_{2} \mathrm{SO}_{4}$ were added, and the suspension was stirred until a homogeneous mixture was obtained. $50 \mathrm{mg}(0.09 \mathrm{mmol})$ of bis(acetal) 4 , dissolved in $10 \mathrm{ml}$ of $\mathrm{CH}_{2} \mathrm{Cl}_{2}$ was added. The mixture was stirred at room temp., the reaction was monitored by TLC and 
complete after $3 \mathrm{~d}$. After filtration water was added and the aqueous layer extracted several times with ethyl acetate. The combined extracts were washed with water and dried with $\mathrm{Na}_{2} \mathrm{SO}_{4}$. The solution was evaporated to dryness at reduced pressure and the residue purified by chromatography (petroleum ether/ethyl acetate $4: 1$ ). Yield: $25 \mathrm{mg}(0.053 \mathrm{mmol})$ of $5(60 \%)$, m. p. $254^{\circ} \mathrm{C}\left(\mathrm{dec}\right.$., $\left.\mathrm{CH}_{2} \mathrm{Cl}_{2}\right)$, $R_{\mathrm{f}}$ 0.30. - UV (Ethanol): $\lambda_{\max }(\lg \varepsilon)=420 \mathrm{~nm}$ (2.466), 321 (3.843), 271 (4.273). $-{ }^{1} \mathrm{H}-\mathrm{NMR}$ (300 MHz): $\delta=3.78$ (s, 4 H, benzyl. $\mathrm{CH}_{2}$ ), $7.34(\mathrm{~d}, 4 \mathrm{H}$, aromat. $\mathrm{H}, J=8 \mathrm{~Hz}), 7.48(\mathrm{t}, 4 \mathrm{H}$, aromat. $\mathrm{H}, J=$ $8 \mathrm{~Hz}), 7.59\left(\mathrm{~s}, 4 \mathrm{H}, \mathrm{H}_{\mathrm{i}}\right), 7.82(\mathrm{~d}, 4 \mathrm{H}$, aromat. $\mathrm{H}, J=8 \mathrm{~Hz})$. - MS: $m / z(\%)=472\left[\mathrm{M}^{+}\right](100), 444(10), 194(9), 193(11), 180(11)$, 179 (16), 165 (15), $106(8), 91$ (28), 90 (44), 89 (28).

\section{$\mathrm{C}_{30} \mathrm{H}_{24} \mathrm{~N}_{4} \mathrm{O}_{2}$ Calcd. 472.18993 Found 472.1899 (MS) \\ Calcd. C 76.25 H 5.12 N 11.86 \\ Found C 76.41 H 5.08 N 12.04}

Photoisomerisation: $5 \mathrm{mg}$ of 5 in $\mathrm{CDCl}_{3}$ was irradiated in a NMR tube for $4 \mathrm{~h}$; photolamp TQ 150/Z 1 (Fa. Original Hanau); selection of the wavelength by UV filter (Schott); $\lambda=443 \mathrm{~nm}\left(T_{\max } 41 \%\right.$, $\mathrm{HW}=14 \mathrm{~nm}), \lambda=369 \mathrm{~nm}\left(T_{\max } 51 \%, \mathrm{HW}=7.9 \mathrm{~nm}\right)$.

\section{CAS Registry Numbers}

1: 121012-95-1 / 2: 126875-84-1 / 3: 126875-85-2 / 4: 126875-86-3 / 5a: 126898-37-1/5b: 126875-87-4 / 5c: 126875-88-5

1) For a review see L. Rossa, F, Vögtle, Top. Curr. Chem. 113 (1983) 1.

${ }^{2)}$ W. Baker, J. F. W. McOmie, W. D. Ollis, J. Chem. Soc. 1951, 200.
3) F. Vögtle, Chem.-Ztg. 96 (1972) 396.

4) 4a) U. Funke, H.-F. Grützmacher, Tetrahedron 43 (1987) 3787.

4b) H.-F. Grützmacher, J. Schmiegel, Chem. Ber. 122 (1989)

1929. - ${ }^{4 c)}$ U. Dittrich, H.-F. Grützmacher, Chem. Ber. 118 (1985) 4404, 4415. - 4d) J. Schmiegel, U. Funke, A. Mix, H.-F. Grützmacher, Chem. Ber. 123 (1990) 1397.

5) 5a) U. Dittrich, Dissertation, Universität Bielefeld, 1984. - ${ }^{\text {5b) }}$ J. Schmiegel, Dissertation, Universität Bielefeld, 1990.

6) S. G. Davies, Organotransition Metal Chemistry. Application to Organic Synthesis, Pergamon Press, Oxford 1982.

7) E. Barroso Lopez, Dissertation, Universität Bielefeld, 1989.

${ }^{8)}$ H. G. Wey, H. Butenschön, Chem. Ber. 123 (1990) 93.

9) 9a) T. A. Weil, L. Cassar, M. Fao in Organic Synthesis via Metallcarbonyls (I. Wender, P. Pino, Eds.), vol. 2, p. 517, Wiley Interscience Publication, New York 1977. - ${ }^{9 b)}$ For a review see P. M. Jolly in Comprehensive Organometallic Chemistry (G. Wilkinson, F. G. A. Stone, E. W. Abel, Eds.), vol. 8, p. 713, Pergamon Press, Oxford 1982.

10) 10 a) A. S. Kunde, R. Greenhouse, J. A. Hill, Tetrahedron Lett. 1979, 2867. - ${ }^{106)}$ N. Satyanarayana, M. Periasamy, Tetrahedron Lett. 1987, 2633. - ${ }^{10 c)}$ P. S. Bratermann, B. S. Walker, T. H. Robertson, J. Chem. Soc., Chem. Commun. 1977, 651.

11) Unpublished results with U. Funke, Universität Bielefeld, 1988.

12) T. H. Chan, M. A. Brook, T. Chaly, Synthesis 1983, 203.

${ }^{13)}$ F. Huet, A. Lechevallier, M. Pellet, J. M. Conia, Synthesis 1978, 63.

${ }^{14)}{ }^{14 a)}$ D. Gräf, H. Nitsch, D. Ufermann, G. Sawitzki. H. Patzelt, H. Rau, Angew. Chem. 94 (1982) 385; Angew. Chem. Int. Ed. Engl. 23 (1982) 373. - ${ }^{14 b)}$ H. Rau, E. Lüddecke, J. Am. Chem. Soc. $104(1982) 1616$.

${ }^{15)}$ N. Tamaoki, K. Koseki, T. Yamaoka, Angew. Chem. 102 (1990) 66; Angew. Chem. Int. Ed. Engl. 29 (1990) 105.

16) R. H. Mitchell in Cyclophanes (P. M. Keehn, S. M. Rosenfeld, Eds.), vol. 1, p. 240, Academic Press, New York 1983.

$[58 / 90]$ 